\title{
Reduction of Localized Abdominal Fat in Men Through the Pulsed and Continuous Application of Combined Therapy Associated With the use of Medium Frequency Excitomotor Current: Randomized Clinical Trial
}

\author{
Amanda Meris Nogueira, ${ }^{1}$ Nathalia Soares de Almeida, ${ }^{2}$ \\ Gabryella Sena Lopes Bonato, ${ }^{2}$ Airan Lobo da Costa, ${ }^{2}$ \\ Matheus Medeiros Costa, ${ }^{2}$ Bruna Corral Garcia de Araujo, ${ }^{2}$ \\ Ana Clara Campagnolo Gonçalves Toledo²
}

\section{ABSTRACT}

The purpose of the study was to evaluate and compare the effects of combined therapy in a continuous and pulsed manner associated with medium-frequency excitomotor current on the reduction of localized fat in men, and its influence on the autonomic, cardiovascular and arterial pressure systems. Containing a sample population of 18 male participants, aged between 18 and 35 years old and with an abdominal fold of up to $4 \mathrm{~cm}$. Divided into two groups, the first one received the application of combined therapy in a pulsed manner and the other one in a continuous manner and both associated with medium frequency excitomotor current. Regardless of the mode of US, there were no changes in systolic and diastolic arterial pressure, in the assessment of the autonomic nervous system, significant but expected values were found.

Keywords: Men; electric stimulation therapy; arterial pressure; localized fat; autonomic nervous system.

REDUÇÃO DA GORDURA ABDOMINAL LOCALIZADA EM HOMENS POR MEIO DA APLICAÇÃO PULSADA E CONTÍNUA DE TERAPIA COMBINADA ASSOCIADA AO USO DA CORRENTE EXCITOMOTORA DE MÉDIA FREQUÊNCIA: ENSAIO CLÍNICO RANDOMIZADO

\section{RESUMO}

O objetivo do estudo foi avaliar e comparar os efeitos da terapia combinada de modo contínuo e pulsado associado a corrente excitomotora de média frequência na redução de gordura localizada em homens, e sua influência no sistema nervoso autônomo, cardiovascular e na pressão arterial. A população amostral incluiu 18 participantes homens, com faixa etária entre 18 e 35 anos e com prega abdominal de até $4 \mathrm{~cm}$. Divididos em dois grupos, o primeiro recebeu a aplicação da terapia combinada de maneira pulsada e o outro de maneira continua e ambos associados à corrente excitomotora de média frequência. Independentemente do modo do US não apresentou alterações na pressão arterial sistólica e diastólica, na avaliação do sistema nervoso autônomo foram encontrados valores significativos, porém esperados.

Palavras-chave: Homem; estimulação elétrica; pressão arterial; gordura localizada; sistema nervoso autônomo.

RECEBIDO EM: 16/11/2020

MODIFICAÇÕES SOLICITADAS EM: 26/6/2021

ACEITO EM: 15/9/2021

\footnotetext{
${ }^{1}$ Autora correspondente. Universidade do Oeste Paulista - Unoeste. R. José Bongiovani, 700 - Cidade Universitária. Presidente Prudente/SP, Brasil. CEP 19050-920. http://lattes.cnpq.br/9892672043664394. https://orcid.org/0000-0001-7122-1474. merisnogueira@gmail.com

2 Universidade do Oeste Paulista - Unoeste. Presidente Prudente/SP, Brasil.
} 


\section{INTRODUCTION}

The distribution of body fat seems to be influenced by factors such as genetics, race and gender, it can be seen that the anatomy and distribution of adipose tissue in men are different from of women, which implies the tendency for men to have fat located in the abdomen. ${ }^{1}$

The increase in adipose tissue in the abdominal region is considered a risk factor for cardiovascular diseases, diabetes, dyslipidemia and metabolic syndrome ${ }^{2,3}$. According to the World Health Organization, 1.9 billion adults are overweight and more than 600 million are obese. Abdominal fat is also a factor that bothers male appearance, so several methods can be used in order to control weight, including behavioral therapies, diets, drug therapy, aesthetics and surgery ${ }^{3}$

The number of men looking for aesthetic and cosmetic interventions grows approximately $10 \%$ per year. According to the American Society for aesthetic plastic surgery. Americans spend more than $\$ 8$ billion a year on cosmetic procedures, with liposuction in men accounting for $12 \%$ in $2019^{4}$

Liposuction is still considered the gold standard for the treatment of excess subcutaneous fat, however due to its invasive nature it retains risks, discomfort and depending on the body of each patient, a long recovery period can occur ${ }^{5}$. Therefore, non-surgical procedures have been shown to be effective in reducing fat in patients reluctant to undergo a surgical procedure ${ }^{6 .}$

In the United States 129,686 non-surgical procedures for reducing abdominal fat were performed in 2019. Noninvasive methods for improving body contour include laser therapy, radiofrequency, cryolipolysis, and electrotherapy. These therapies result in fewer complications than liposuction ${ }^{2}$

Among the aesthetic concerns is also the muscular flaccidity that acts directly on the adjacent tissues and facilitating the accumulation of fats. The medium frequency excitomotor current was created to fill a gap in aesthetic treatment, since used in combination with other therapies it favors satisfactory results with the increase of hypertrophy and muscular strength. ${ }^{7}$

In detriment to the desire to develop non-invasive methods to reduce local deposits of fatty tissue, the advancement of aesthetics is increasing in this sector, making studies necessary to prove the efficacy and safety of new therapies. $^{7}$

Due to the application of the combination therapy intervention and medium frequency excitomotor current, there may be changes in the organism, which may or may not change the behavior of the central nervous system (CNS) and the autonomic nervous system (ANS) in order to make local cardiovascular adjustments, as well as maintaining its homeostasis. ${ }^{8}$

This study aims to evaluate the effectiveness of combined therapy using ultrasound in continuous and pulsed modes associated with medium frequency excitomotor current to reduce abdominal fat in men, as well as to assess whether the association of both techniques are able to promote changes in the parameters of heart variability and blood pressure.

Editora Unijuí - Revista Contexto \& Saúde - ISSN 2176-7114 - v. 21, n. 44, out./dez. 2021 


\section{METHODS}

This study is registered on the OSF platform, performed retrospectively and approved under the code 8gmvf. Data collection was carried out in the clinical practices laboratory of the University of Western Paulista (UNOESTE) - Campus 1. Participants were informed about the objectives and procedures to be carried out in the present study, signed a free and informed consent form. The procedures used to carry out this work were evaluated by the Research Ethics Committee of the University of Western Paulista- UNOESTE / Presidente Prudente (CAAE: 88846418.0.0000.5515).

\section{POPULATION AND SAMPLE}

This is a randomized clinical trial reported in accordance with the CONSORT Checklist. It contains a sample population of 18 participants included according to the following criteria, men, aged between 18 and 35 years old and with an abdominal fold of up to $4 \mathrm{~cm}$. To conduct the study, the international physical activity questionnaire (IPAQ) in its short version was completed in order to classify their levels of physical activity as sedentary, insufficiently active A or B.

The collections were carried out between the period of March 2018 until November 2019, with their return expected in March 2020, when quarantine started due to COVID-19, thus interrupting the continuity of data collection.

The formation of groups were randomized by drawing lots, with no blinding on the part of the participants or researchers. Protocol 1 or protocol 2, the first group received application of combined therapy in a continuous manner associated with medium frequency excitomotor current CCT $+\mathrm{CR}$, the second group received application of combined therapy in a pulsed way associated with medium frequency excitomotor current PCT + CR, (Figure 1)

Figure 1 - Organization chart of randomization

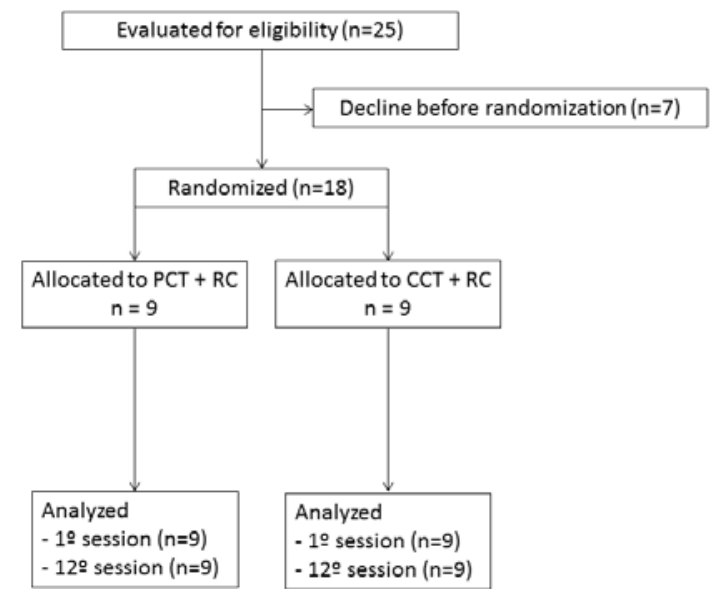

Abbreviations: CCT + CR: Continuous combination therapy; PCT + CR: Continuous combined therapy with Russian current.

In the present study, participants were not included, classified as active or very active according to the IPAQ questionnaire, smokers, alcohol users and who used medication or pathologies that interfered with the cardiovascular, respira- 
tory, metabolic system and also had any contraindications to the use of combination therapy. and neuromuscular electrostimulation.

\section{INITIAL AND FINAL EVALUATION}

The initial and final evaluations were carried out by a single trained evaluator. Participants were instructed to remain for 24 hours without alcohol and / or caffeine, so that there was no influence on the autonomic nervous system. ${ }^{9}$

The abdominal skinfold was evaluated by means of an adipometer (Sanny, Brazil) (approximate pressure of $10 / \mathrm{mm} 2$ and division of $0.1 \mathrm{~mm}$ ) in the participant's right hemibody in the standing position, this measurement was repeated 3 times, being considered the average of these values.

After validation of the inclusion criteria, the next step was the anthropometric analysis, performed before the first and after the last session of the intervention.

To measure weight and height, participants remained in an upright position, $\mathrm{BMI}$ was determined using the following formula $\mathrm{BMI}=$ weight $(\mathrm{kg}) /$ height (m2), according to the Brazilian Association for the Study of Obesity. ${ }^{10}$

The perimeter of the abdomen, waist and hips were measured using a tape measure (Sanny, Brazil). For abdomen measurements, three different areas were performed: upper abdomen: $2.5 \mathrm{~cm}$ above the umbilical scar, middle abdomen: tape over the umbilical scar and lower abdomen: $2.5 \mathrm{~cm}$ below the umbilical scar. The waist was considered the place with the smallest circumference below the chest. For the hip, it was performed with the feet together and the tape was positioned over the pubic symphysis (anteriorly) and over the maximum gluteal profusion (posteriorly).

Arterial pressure were measured before and after the intervention over the 12 sessions using a stethoscope and aneroid sphygmomanometer attached to the participants' left arm according to the VI Brazilian Guidelines on Hypertension. ${ }^{11}$

\section{EXPERIMENTAL PROTOCOL}

In both groups, the intervention was performed using the Manthus device ( $K L D$ biosystems, Brazil) offering the combined application of ultrasound ( $3 \mathrm{MHz}$, $45 \mathrm{~W}$ ) and stereodynamic current (10 to $15 \mathrm{~Hz}$, sinusoidal shape). The total application time was 8 minutes in the abdominal region.

For the application of medium frequency excitomotor current, the Neurodyn-10 channels ${ }^{\circledR}$ medium frequency electrostimulation device, manufactured by IBRAMED Ltda, was used. The following parameters were used: Carrier frequency of 2,500 Hz, modulated frequency of $100 \mathrm{~Hz}$, phase (cycle) of $50 \%$, resting contraction time of 6 seconds, for 20 minutes at an intensity $(\mathrm{mA})$ sufficient to provide visible contraction. ${ }^{12}$

The intervention of both groups began with the placement of the Polar ${ }^{\circledR}$ SR800 cardiofrequency meter and watch (Polar Electro OY, Finland) used for HRV analysis on the participants' chest and wrist. After that, they were instructed to remain in the supine position for 10 minutes before and after the intervention.

For time and frequency domain analysis respectively: RMSSD (at the square root of the square mean of the differences between adjacent normal RR in- 
tervals in a time interval expressed in milliseconds [ms]) and SDNN (standard deviation of all normal RR intervals recorded in a time interval, expressed in $\mathrm{ms}$ ). ${ }^{3}$, ${ }^{13} \mathrm{LF}$ (Low frequency between 0.04 to $0.15 \mathrm{~Hz}$ ), HF (High frequency between 0.15 to $0.4 \mathrm{~Hz}$ ), in normalized units and in ms squared, and the ratio between these components (LF / HF) ${ }^{12}$ the final 10 minutes of the rest period were extracted, the first 5 minutes were excluded and only the final 5 minutes were analyzed.

For the recovery period 1 (Rec 1 ) the first 5 minutes were defined after the end of the intervention and recovery 2 (Rec 2 ) was defined as the final 5 minutes. Enabling the analysis of HRV indices using the Kubios HRV software- version 2.0 (Kubios, Biosignal Analysis and Medical Image Group, Department of Physics, University of Kuopio, Finland) generating the values of the time and frequency domain, which is calculated through a tachogram using the Fast Fourier transform algorithm. ${ }^{3,14}$

\section{Statistical analysis}

For the population profile data, the descriptive statistical method was used and the results were presented with values of means, standard deviations, medians, minimum and maximum numbers. The normality of the data was assessed using the Kolmogorov-Smirnov test. For the analysis of anthropometric measurements, the Wilcoxon test was used for data with non-normal distribution and Student's $t$ test for paired data when the distribution was normal.

In evaluating the comparison of arterial pressure values and HRV variables, the variance technique was used for the Anova One-Way repeated measures model or Kruskall Wallis test. The level of significance was set at $p<0.05$ for all tests Heart rate variability data was transferred to Polar Precision Performance SW software, version 3.0

\section{RESULTS}

The present study had a total of 18 men who agreed to participate in the research, with 9 individuals in the CCT $+\mathrm{CR}$, group and 9 individuals in the PCT + $\mathrm{CR}$, group. (Table 1 )

Table 1 - Baseline demographic data and clinical characteristics $(N=18)$.

\begin{tabular}{|c|c|c|}
\hline Personal characteristics & $(\mathrm{PCT}+\mathrm{RC})$ & (CCT + RC) \\
\hline \multicolumn{3}{|l|}{ Sample } \\
\hline Age & $\mathrm{N}=9$ & $\mathrm{~N}=9$ \\
\hline Systolic Arterial pressure & $23,33 \pm 4,69$ & $24,11 \pm 3,98$ \\
\hline \multirow[t]{2}{*}{ Diastolic Arterial pressure } & $111.11 \pm 9.28$ & $114.44 \pm 7.26$ \\
\hline & $76.67 \pm 10.00$ & $78.89 \pm 3.33$ \\
\hline $\mathrm{BMI}\left(\mathrm{Kg} / \mathrm{m}^{2}\right)$ & $23.40 \pm 2.17$ & $23.55 \pm 2.54$ \\
\hline Abdominal skinfold $(\mathrm{cm})$ & $2.51 \pm 0.96$ & $2.66 \pm 1.05$ \\
\hline Weight (Kg) & $73.97 \pm 8.67$ & $73.72 \pm 8.13$ \\
\hline Abdominal Perimeter & $86.72 \pm 7.69$ & $88.28 \pm 8.03$ \\
\hline Waist & $80.72 \pm 5.90$ & $80.16 \pm 6.21$ \\
\hline Hip & $98.39 \pm 4.99$ & $98.44 \pm 7.15$ \\
\hline IPAQ - irregularly active A & $44.44 \%$ & $22.22 \%$ \\
\hline IPAQ - insufficient active B & $55.56 \%$ & $66.67 \%$ \\
\hline IPAQ - sedentary & $0 \%$ & $11.11 \%$ \\
\hline
\end{tabular}

Legend: average values, followed by the respective standard deviations. 
The values of anthropometric measurements of 18 men before and after twelve therapy sessions combined in a continuous or pulsed manner associated with the medium frequency excitomotor current are presented in mean values, followed by the respective standard deviations, median, minimum and maximum values in table 2 . Were found significant differences in the abdominal skinfold and waist variables of the PCT $+C R$, group. No significant differences were found in the other characteristics assessed within and between groups.

Table 2 - presents mean values, followed by the respective standard deviations, median, minimum and maximum values of the initial and final anthropometric measurements in intergroup and group comparisons.

\begin{tabular}{|c|c|c|c|c|}
\hline \multirow[b]{2}{*}{ Personal characteristics } & \multicolumn{4}{|c|}{ Intergroup Comparison } \\
\hline & $\begin{array}{c}1 \text { Session } \\
(\mathrm{PCT}+\mathrm{RC})\end{array}$ & $\begin{array}{l}12 \text { Session } \\
(\mathrm{PCT}+\mathrm{RC})\end{array}$ & $\begin{array}{c}1 \text { Session } \\
(C C T+R C)\end{array}$ & $\begin{array}{l}12 \text { Session } \\
(C C T+R C)\end{array}$ \\
\hline $\mathrm{BMI}\left(\mathrm{Kg} / \mathrm{m}^{2}\right)$ & $\begin{array}{c}23.40 \pm 2.17 \\
23.90 \\
{[20.00-26.40]}\end{array}$ & $\begin{array}{c}23.19 \pm 2.26 \\
24.00 \\
{[20.20-25.70]}\end{array}$ & $\begin{array}{c}23.55 \pm 2.54 \\
24.30 \\
{[18.10-25.90]}\end{array}$ & $\begin{array}{c}23.63 \pm 2.85 \\
24.70 \\
{[17.90-26.40]}\end{array}$ \\
\hline Abdominal skinfold (cm) & $\begin{array}{c}2.51 \pm 0.96{ }^{*} \\
2.10 \\
{[1.40-4.00]}\end{array}$ & $\begin{array}{c}2.26 \pm 0.88^{*} \\
2.00 \\
{[1.10-3.50]}\end{array}$ & $\begin{array}{c}2.66 \pm 1.05 \\
3.00 \\
{[0.80-3.90]}\end{array}$ & $\begin{array}{c}2.56 \pm 0.97 \\
2.60 \\
{[1.00-4.00]}\end{array}$ \\
\hline Weight (Kg) & $\begin{array}{c}73.97 \pm 8.67 \\
73.00 \\
{[56.00-84.80]}\end{array}$ & $\begin{array}{c}73.53 \pm 8.45 \\
72.00 \\
{[56.50-84.20]}\end{array}$ & $\begin{array}{c}73.72 \pm 8.13 \\
74.20 \\
{[60.00-83.70]}\end{array}$ & $\begin{array}{c}74.01 \pm 8.71 \\
76.50 \\
{[59.50-83.90]}\end{array}$ \\
\hline Abdominal Perimeter & $\begin{array}{c}86.72 \pm 7.69 \\
89.00 \\
{[75.00-96.00]}\end{array}$ & $\begin{array}{c}86.44 \pm 7.09 \\
85.00 \\
{[75.00-97.00]}\end{array}$ & $\begin{array}{c}88.28 \pm 8.03 \\
90.00 \\
{[76.00-97.00]}\end{array}$ & $\begin{array}{c}88.89 \pm 7.65 \\
92.00 \\
{[75.00-96.00]}\end{array}$ \\
\hline Waist & $\begin{array}{c}80.72 \pm 5.90 * \\
82.50 \\
{[70.00-87.50]}\end{array}$ & $\begin{array}{c}78.61 \pm 5.08^{*} \\
77.50 \\
{[70.00-84.50]}\end{array}$ & $\begin{array}{c}80.16 \pm 6.21 \\
81.00 \\
{[72.00-91.00]}\end{array}$ & $\begin{array}{c}79.11 \pm 7.59 \\
81.00 \\
{[68.00-90.00]}\end{array}$ \\
\hline Hip & $\begin{array}{c}98.39 \pm 4.99 \\
98.00 \\
{[90.00-105.50]}\end{array}$ & $\begin{array}{c}97.06 \pm 5.26 \\
97.00 \\
{[87.00-105.00]}\end{array}$ & $\begin{array}{c}98.44 \pm 7.15 \\
100.00 \\
{[89.00-108.50]}\end{array}$ & $\begin{array}{c}96.16 \pm 8.95 \\
97.00 \\
{[80.00-106.00]}\end{array}$ \\
\hline IPAQ - irregularly active $A$ & $\begin{array}{l}44.44 \% \\
55.56 \%\end{array}$ & ----- & $\begin{array}{l}22.22 \% \\
66.67 \% \\
11.11 \%\end{array}$ & ----- \\
\hline IPAQ - insufficient active B & $0 \%$ & ---- & & ----- \\
\hline IPAQ - sedentary & & ----- & & ----- \\
\hline
\end{tabular}

The indexes in the frequency domain ( $\mathrm{HF}$ un and $\mathrm{HF} \mathrm{ms}^{2}$ ) are presented in average values, followed by the respective standard deviations, median, minimum and maximum values. For the values of the variable HF un in the comparison between rec1 and the rest of the PCT $+C R$, group, significant differences were found in Table 3. No significant differences were found in the HFms2 index when comparing the first intragroup session and between groups. 
Table 3 - presents mean values, followed by the respective standard deviations, median, minimum and maximum values of the indexes in the time domain

(RMSSD and SD1), indexes in the frequency domain ( $\mathrm{HF}$ un and $\mathrm{HF} \mathrm{ms}^{2}$ ) of the first session of both groups

\begin{tabular}{ccccc}
\hline Moments & \multicolumn{4}{c}{$\begin{array}{c}\text { Intergroup Comparison } \\
\text { Session } 1(\mathrm{PCT}+\mathrm{RC})\end{array}$} \\
\hline & $\mathrm{RMSSD}$ & $\mathrm{SD} 1$ & $\mathrm{HF}$ (un) & $\mathrm{HF}(\mathrm{ms})$ \\
Rest & $51.42 \pm 24.60$ & $36.41 \pm 17.42$ & $55.58 \pm 15.97^{*}$ & $1168 \pm 1031.3$ \\
& 45.60 & 32.30 & 59.35 & 786 \\
& {$[28.30-99.20]$} & {$[20.00-70.20]$} & {$[30.98-78.89]$} & {$[177-3121]$} \\
& & & & \\
M1 & $53.82 \pm 19.82$ & $38.12 \pm 14.04$ & $40.55 \pm 13.38^{*}$ & $1036.77 \pm 767.78$ \\
& 48.30 & 34.20 & 42.35 & 894 \\
& {$[33.20-99.10]$} & {$[23.50-70.20]$} & {$[20.91-56.82]$} & {$[268-2646]$} \\
M 2 & $53.94 \pm 21.17$ & $38.20 \pm 15.00$ & $47.87 \pm 21.35$ & $1322.67 \pm 1566.00$ \\
& 46.30 & 32.80 & 42.49 & 876 \\
& {$[34.80-102.20]$} & {$[24.70-72.40]$} & {$[23.32-77.22]$} & {$[431-5282]$} \\
\hline
\end{tabular}

Abbreviations: RMSSD: mean square root of the sum of the squares of difference between adjacent RR intervals; SD1: beat-to-beat variability; HF: high frequency power; un: standard units; ms2 milliseconds squared; M1: recovery time 1; M2: moment of recovery 2. * Significant differences between rest and M1 (Analysis of variance test for repeated measures ANOVA with Bonferroni post test, $p<0.05$ ).

Table 4 - shows mean values, followed by the respective standard deviations, median, minimum and maximum values, the significant differences for the PCT + $\mathrm{CR}$, group, in the variable RMSSD and SD1 at times rec 1 and rec 2 when compared to the rest and $\mathrm{HF} \mathrm{ms}^{2}$ between rest and rec 1 . In the CCT + CR, group, significant differences were found in the variables RMSDD, SD1 and HF un compared to rec1. No significant differences were found between groups.

\begin{tabular}{ccccc}
\hline Moments & \multicolumn{4}{c}{$\begin{array}{c}\text { Intergroup Comparison } \\
\text { Session 1 (PCT + RC) }\end{array}$} \\
\hline & RMSSD & SD1 & HF (un) & HF (ms) \\
& $51.42 \pm 24.60$ & $36.41 \pm 17.42$ & $55.58 \pm 15.97^{*}$ & $1168 \pm 1031.3$ \\
Rest & 45.60 & 32.30 & 59.35 & 786 \\
& {$[28.30-99.20]$} & {$[20.00-70.20]$} & {$[30.98-78.89]$} & {$[177-3121]$} \\
& & & & \\
M 1 & $53.82 \pm 19.82$ & $38.12 \pm 14.04$ & $40.55 \pm 13.38^{*}$ & $1036.77 \pm 767.78$ \\
& 48.30 & 34.20 & 42.35 & 894 \\
& {$[33.20-99.10]$} & {$[23.50-70.20]$} & {$[20.91-56.82]$} & {$[268-2646]$} \\
M 2 & $53.94 \pm 21.17$ & $38.20 \pm 15.00$ & $47.87 \pm 21.35$ & $1322.67 \pm 1566.00$ \\
& 46.30 & 32.80 & 42.49 & 876 \\
& {$[34.80-102.20]$} & {$[24.70-72.40]$} & {$[23.32-77.22]$} & {$[431-5282]$} \\
\hline
\end{tabular}

Abbreviations: RMSSD: mean square root of the sum of the squares of difference between adjacent RR intervals; SD1: beat-to-beat variability; HF: high frequency power; un: standard units; ms2 milliseconds squared; M1: recovery time 1; M2: moment of recovery 2. ${ }^{*}$ Significant differences between rest and M1 (Analysis of variance test for repeated measures ANOVA with Bonferroni post test, $p<0.05$ ).

Table 4- presents mean values, followed by the respective standard deviations, median, minimum and maximum values of the indexes in the time domain (RMSSD and SD1), indexes in the frequency domain ( $\mathrm{HF}$ un and $\mathrm{HF} \mathrm{ms}^{2}$ ) from the last session of both groups. 
The results for the time domain indexes are presented in mean values, followed by the respective standard deviations, median, minimum and maximum values, in table 5 significant differences were found in the SDNN and SD2 variables between the moments of rec1 and rec2 compared to rest, LF un between the moments of rec 1 and rest and LF ms ${ }^{2}$ between the moments of rec 1 and rec2 compared to the rest of the PCT + CR, group. No significant differences were found in the comparisons between groups.

Table 5 - presents mean values, followed by the respective standard deviations, median, minimum and maximum values of the indexes in the time domain (SDNN and SD2), indexes in the frequency domain (LF un and LF ms) of the first session of both groups

\begin{tabular}{ccccc}
\hline \multirow{2}{*}{ Moments } & \multicolumn{4}{c}{ Intra-Group Comparison } \\
\cline { 2 - 5 } & SDNN & SD2 & LF (un) & LF (ms) \\
\hline \multirow{2}{*}{ Rest } & $43.77 \pm 16.34^{*+}$ & $49.74 \pm 16.35^{*+}+$ & $44.18 \pm 16.03^{*}$ & $717.33 \pm 458.91^{*+}$ \\
& 35.00 & 42.50 & 40.59 & 555 \\
& {$[29.00-75.40]$} & {$[33.70-80.40]$} & {$[20.38-68.73]$} & {$[324-1695]$} \\
& \multicolumn{4}{c}{} \\
Rescovery 1 & $56.41 \pm 15.41^{*}$ & $63.33 \pm 17.59^{*}$ & $59.35 \pm 13.43^{*}$ & $1316.22 \pm 602.18^{*}$ \\
& 52.41 & 59.40 & 57.64 & 1331 \\
& {$[34.60-88.20]$} & {$[41.50-103.10]$} & {$[43.04-79.09]$} & {$[670-2618]$} \\
Rescovery 2 & $52.52 \pm 15.80^{*+}$ & $63.13 \pm 18.43^{+}$ & $51.99 \pm 21.41$ & $1179.67 \pm 652.06^{+}$ \\
& 47.80 & 59.20 & 57.48 & 1416 \\
& {$[33.40-84.00]$} & {$[40.00-94.30]$} & {$[22.39-76.56]$} & {$[266-2170]$} \\
\hline
\end{tabular}

Abbreviations: SDNN: standard deviation in all RR intervals; SD2: variability in long-term records; LF: low frequency power; un: standard units; ms2 milliseconds squared; M1: recovery time 1; M2: moment of recovery 2. * Significant differences between rest and M1; † Significant differences between rest and M2. (Analysis of variance test for repeated ANOVA measurements with Bonferroni post test, $p<0.05$ ).

Table 6 shows average values, followed by the respective standard deviations, median, minimum and maximum values of the indexes in the time domain (SDNN and SD2), indexes in the frequency domain (LF un and LF ms). In the SDNN variables, significant differences were found in the comparison between the moments of rec 1 and rec 2 compared to rest, SD2 between the moments of rec 1 in relation to the rest of the PCT + CR, group. In the CCT + CR, group, in the variables SDNN, SD2 and LF un between rec 1 moments compared to rest. No significant differences were found in the other intra-group comparisons or in the comparisons between groups. 


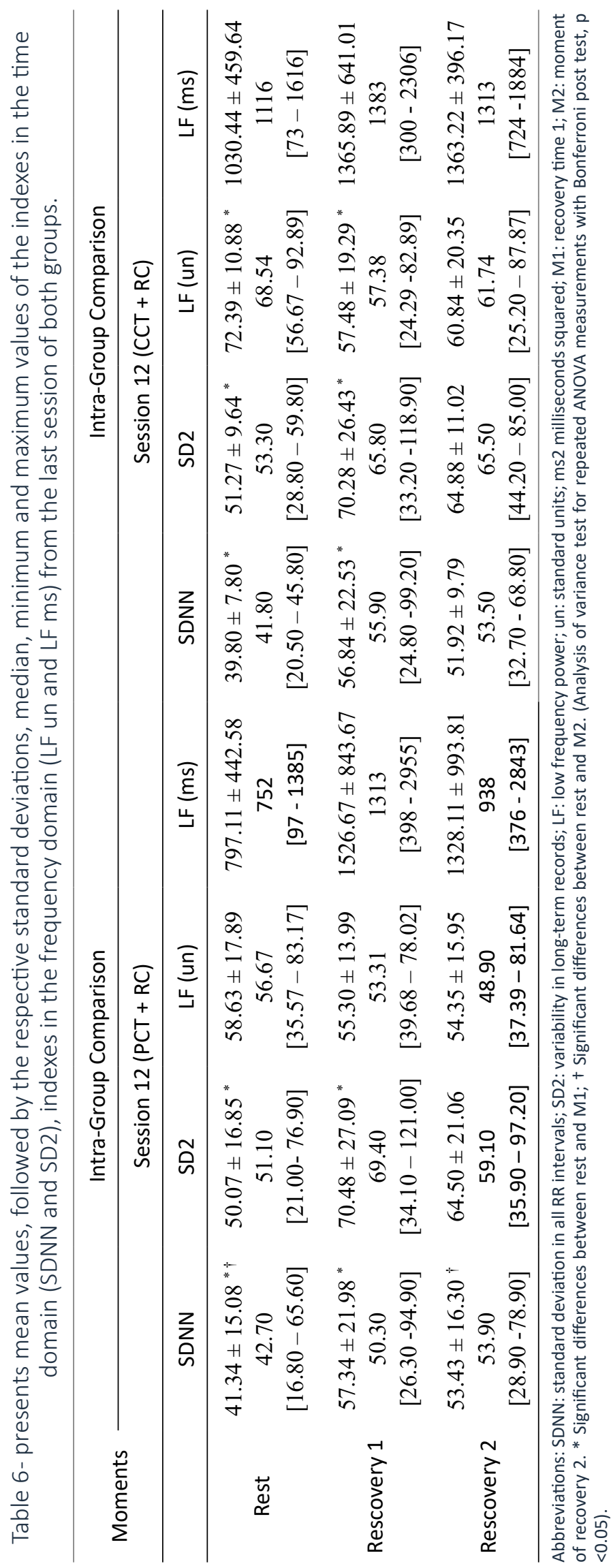




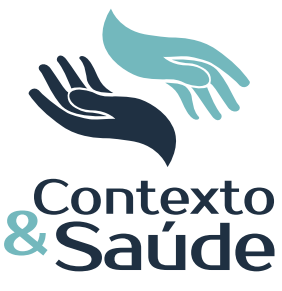

\section{DISCUSSION}

The results presented after the treatment of 10 sessions of combined and pulsed therapy combined with the medium-frequency excitomotor current mobilized the Autonomic Nervous System throughout its application and the group that carried out the combined therapy in a pulsed manner reached a recovery period longer when compared to the group that performed the treatment in continuous mode. It is believed that the inclusion of electrical stimulation therapy after combined therapy with the objective of promoting the energy expenditure of the lipids released by the combined therapy, thus replacing an isometric exercise, may have been responsible for the significant autonomic changes observed in the period recovery by the behavior of HRV indexes that represent parasympathetic and global activity.

Ultrasound, present in combined therapy, promotes cellular permeability, helps in the circulation of intra and extracellular fluids caused by the mechanical effect of vibration due to its waves that generate stable cavitation that promotes the formation of bubbles in fat cells inducing lipolysis. In addition to this, it also promotes the thermal effect when used in continuous mode causing an increase in local temperature helping to break down triglycerides within the adipocyte. ${ }^{2,7}$

The medium-frequency excitomotor current was used to promote the caloric expenditure of fatty acids released into the bloodstream after application of the combined therapy inducing muscle strengthening. ${ }^{15}$

The PCT + CR group showed a decrease in abdominal skinfolds and waist measurements, as did the study by Costa et al., $2016{ }^{16}$, carried out with the equipment in continuous mode, which showed a reduction in these measurements, although the comparisons did not show statistical differences before and after the intervention, a fact that can be justified by the influence of the hormonal action, since the sample was composed of women, different from the present study, being one of the main differences.

The influence of the hormonal action of testosterone can justify the results of decreased measurements in women when applied to the combined therapy in continuous mode, differently from when applied in men. This is because testosterone acts to reduce the activity of lipoprotein lipase (LPL) in adipose tissue, which is the most important regulator for the deposition of triglycerides. ${ }^{17}$

Another study by Costa et al., 2014, ${ }^{18}$ investigated combined therapy through a case report of 2 women, who did not obtain significant differences in their anthropometric measurements, however, it is possible to observe reductions in the perimeter measurements such as waist, upper abdomen and lower, as well as abdominal skin folds and supra iliac. Such effects are justified by the thermal effects on the tissues and consequently to the increase in heat such as vasodilation, increased blood flow and permeability.

Another study showing positive results with isolated pulsed-mode combined therapy was coordinated by Presotto et al., 2018, ${ }^{15}$ with a sample of 20 healthy women, showing a significant decrease in the thickness of abdominal and supra iliac subcutaneous fat. The effects of the combined therapy were jus-

Editora Unijuí - Revista Contexto \& Saúde - ISSN 2176-7114 - v. 21, n. 44, out./dez. 2021 


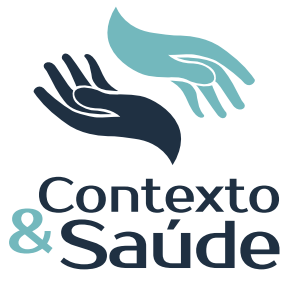

tified by the authors by the increase in total cholesterol levels, demonstrating that the fatty acids were released by lipolysis of the adipocytes. Catecholamines, epinephrine and norepinephrine work in the adipocyte cell membrane channels, promoting mobilization of adipocyte content. Due to this, the authors hypothesis is that the effects of ultrasound waves and electrical stimulation cause an increase in the release of norepinephrine in the extracellular fluid.

HRV performs the assessment of normal or non-abnormal heart rate changes, in relation to physiological and environmental changes, such as breathing, mental, metabolic stress, sleep, due to illness and practicing physical exercise. ${ }^{12}$

Added that, a significant increase was observed in the values of the indexes that represent parasympathetic activity (RMSSD, SD1, HF un and HF ms) when the moment of recovery is compared to the moments of rest after the last session, regardless of the mode of US being continuous or pulsed.

During exercise, its intensity can produce responses such as decreased parasympathetic activity and increased sympathetic activity. ${ }^{7}$ After the interruption of isometric exercise through medium-frequency excitomotor current, there is an increase in venous return and BP, stimulating vagal resumption that progressively decreases until its complete removal, thus reestablishing these parameters at rest, determined by the increase of the parasympathetic autonomic system, together with the reduction of the sympathetic autonomic system.

This is the first study to analyze changes in HRV after the intervention of combination therapy, ultrasound or medium frequency excitomotor current in a male population. In the study by CAMARGO et al. ${ }^{19}$ the acute effects of HRV after a lymphatic drainage session were evaluated, in the group with male population, in relation to the variables of the time domain there was a small difference, but not significant and did not present changes in the frequency domain, different from the present study.

The changes in the parasympathetic and sympathetic autonomic nervous system were not enough to alter the participants' systolic and diastolic arterial pressure values, being considered a beneficial result, since the combination of the devices did not present risks for the population of this study. It can be used as a therapy associated with exercise or diet, favoring the improvement of the quality of life of eutrophic and sedentary individuals, helping to reduce them.

The importance of this study for the area of body aesthetics is to provide the basis for other studies, as they are scarce in relation to the male population.

\section{LIMITATIONS}

In the present study, the loss of the sample and the difficulty in finding sedentary male participants can be observed as limitations. There are several electrotherapeutic resources for body aesthetics and this is the first study that evaluates cardiac autonomic modulation after the application of combined therapy treatment associated or not with medium-frequency excitomotor current, there are few scientific studies with many limitations such as lack of control group, male population and small sample due to dropouts throughout the work. 


\section{CONCLUSION}

This article evaluated the combined aesthetic therapy equipment consisting of $3 \mathrm{Mhz}$ ultrasound with stereodynamic current, in pulsed and continuous modes for each group associated with medium frequency excitomotor current. Regardless of the US mode, there were no changes in systolic and diastolic blood pressure, in the assessment of the autonomic nervous system, significant values were found, but expected. Regarding the reduction of localized fat, the group that received the application of the combined therapy in a pulsed way associated with medium frequency excitomotor current, presented a significant decrease in anthropometric measurements in relation to the other group. Therefore, studies with cardiac and/or hypertensive populations are needed, which can guarantee their well-being in face of aesthetic electrotherapies. As well as performing new methodologies with the use of pulsed mode therapy.

\section{INTEREST CONFLICTS}

The authors declare that there was no conflict of interest.

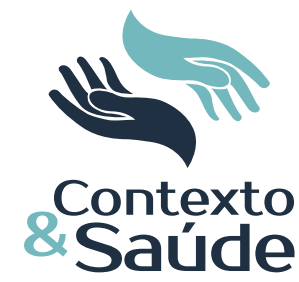

\section{REFERENCES}

${ }^{1}$ Karcher C. Liposuction Considerations in Men. Dermatologic Clinics. 2018;36(1):75-80 doi: 0.1016/j.det.2017.09.010

${ }^{2}$ Neeland IJ, Ross R, Després JP, Matsuzawa Y. International Atherosclerosis Society; International Chair on Cardiometabolic Risk Working Group on Visceral Obesity. Visceral and ectopic fat, atherosclerosis, and cardiometabolic disease: a position statement. Lancet Diabetes Endocrinol. 2019, 7(9):715-725. doi: 10.1016/S2213-8587(19)30084-1

3 Norbert SN. Causes, consequences, and treatment of metabolically unhealthy fat distribution. Lancet Diabetes Endocrinol. 2020;8(7)616-627. doi: 10.1016/S22138587(20)30110-8

${ }^{4}$ The american society for aesthetic plastic surgery. Aesthetic plastic surgery national databank statistics. 2020.

5 Wu S, Coombs DM, Gurunian R. Liposuction: Concepts, safety, and techniques in body-contouring surgery. Cleve Clin J Med. 2020;87(6)367-375 doi: 10.3949/ ccjm.87a.19097

${ }^{6}$ Rice TM, Lee JYW, Brier T, Saito R, Hsu CK. Current Evidence in Nonsurgical Fat Reduction. Advances in Cosmetic Surgery. 2018;1(1)55-66 doi: 10.1016/j.yacs.2018.02.010

${ }^{7}$ Modesto KAG, de Oliveira PFA, Fonseca HG, Azevedo KP, Guzzoni V, Bottaro M, Babault N, Durigan JLQ. Russian and Low-Frequency Currents Induced Similar Neuromuscular Adaptations in Soccer Players: A Randomized Controlled Trial. J Sport Rehabil. 2019;18(29):594-601 doi: 10.1123/jsr.2018-0314

8 Gonzaga LA, Vanderlei LCM, Gomes RL, Garner DM, Valenti VE. Involvement of Cardiorespiratory Capacity on the Acute Effects of Caffeine on Autonomic Recovery. Medicina (Kaunas). 2019;23(55):196 doi: 10.3390/medicina55050196

${ }^{9}$ Gonzaga LA, Vanderlei LCM, Gomes RL, Valenti VE. Caffeine affects autonomic control of heart rate and blood pressure recovery after aerobic exercise in young adults: a crossover study. Sci Rep. 2017;26(7)14091 doi: 10.1038/s41598-017-14540-4

${ }^{10}$ Associação Brasileira para o Estudo da Obesidade e da Síndrome Metabólica (Abeso). Diretriz Brasileiras de Obesidade. 4. ed. São Paulo: Abeso; 2016.

${ }^{11}$ Barroso WKS. Diretrizes Brasileiras de Hipertensão Arterial - Diretrizes Brasileiras de Hipertensão Arterial - 2020. Arq. Bras. Cardiol. 2021;116(3):516-658. 
12 Tassinary J. Raciocínio clínico aplicado à Estética Corporal. Estética Experts. 1. ed.; 2018.

${ }^{13}$ Moors S, Staaks KJJ, Westerhuis MEMH, Dekker LRC, Verdurmen KMJ, Oei SG, van Laar JOEH. Heart rate variability in hypertensive pregnancy disorders: A systematic review. Pregnancy Hypertens. 2020;20:56-68. doi: 10.1016/j.preghy.2020.03.003

${ }^{14}$ Benjamim CJR, Kliszczewicz B, Garner DM, Cavalcante TCF, da Silva AAM, Santana MDR, Valenti VE. Is Caffeine Recommended Before Exercise? A Systematic Review To Investigate Its Impact On Cardiac Autonomic Control Via Heart Rate And Its Variability. J Am Coll Nutr. 2020;39(6):563-573. doi: 10.1080/07315724.2019.1705201

15 Presotto, L. Rogeri L, Sinigaglia G. Aesthetic Nonthermal Ultrasound and Electric Current Combination Therapy for Body Sculpting. Cosmetol J. 2018;2(1).

${ }^{16}$ Costa RB, Garcez VF, Limana MD. Terapia combinada (ultrassom e eletroterapia) na redução da adiposidade abdominal: relato de casos. ConsSaude. 2016;15(4):665-670. doi:10.5585/ConsSaude.v15n4.6671

${ }^{17}$ Santosa S, Bush NC, Jensen MD. Acute Testosterone Deficiency Alters Adipose Tissue Fatty Acid Storage. J Clin Endocrinol Metab. 2017;1(102):3056-3064. doi: 10.1210/ jc.2017-00757

${ }^{18}$ Costa RB, Garcez VF, Silva GMA. Efeitos das terapias combinadas ultrassom + Corrente Aussie e ultrassom + Corrente Estereodinâmica no tratamento de gordura abdominal: estudo de casos. Rev. Bras. Pesq. Saúde, Vitória. 2014;16(4):136-144.

${ }^{19}$ Camargo EAM, Gomes-Marcondes MCC. Estudo da eficácia da drenagem linfática manual na mobilização hidroeletrolítica, na taxa lipolítica e na variabilidade da frequência cardíaca em homens e mulheres. Campinas. [Tese Doutorado] - Universidade de Campinas; 2015. 